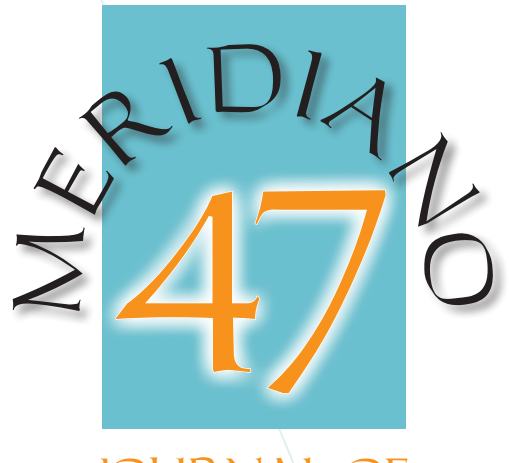

JOURNAL OF

GLOBAL STUDIES

ISSN 1518-1219

http://www.meridiano47.info

Marcelo Antonio Osller Malagutti

Kings College London, Department of War Studies, Londres - Reino Unido

E-mail: (marcelo.malagutti@ludicity.com.br).

iD ORCID ID:

https://orcid.org/0000-0002-2969-7871

\section{Agradecimentos}

Esta pesquisa contou com o apoio da Coordenação de Aperfeiçoamento de Pessoal de Nível Superior (Capes)

\title{
Como a Política e a Estratégia Nacionais de Defesa de 2016 dialogam entre si?
}

\section{How do the Brazilian 2016 National Policy and Strategy of Defence dialogue with each other?}

DOI: http://dx.doi.org/10.20889/M47e22005

Recebido em 12 de julho de 2020

Aprovado em 2 de novembro de 2020

\section{Resumo}

Os assim-chamados Documentos de Defesa brasileiros permitem o aprofundamento do debate sobre o tema pela sociedade. Entretanto, mesmo em sua terceira geração, ainda apresentam erros e inconsistências na forma e na coerência, interna e entre si, chegando por vezes a serem contraditórios. Este artigo aponta situações presentes nos dois documentos de mais alto nível, a Política e a Estratégia, e propõe algumas melhorias simples que buscam ampliar a objetividade e a consistência dos referidos documentos.

\section{Abstract}

The so-called Brazilian Defence Documents allow society to deepen the debate on the topic. However, even in their third generation, they still have errors and inconsistencies in form and coherence, internally and with each other, sometimes even being contradictory. This article points out situations present in the two highest-level documents, Policy and Strategy, and proposes some simple improvements that seek to increase the objectivity and consistency of those documents.

Palavras-chave: Defesa Nacional; Estratégia; Políticas Públicas.

Keywords: National Defence; Public Policies; Strategy.

\section{Introdução}

- This is an open-access article distributed under the terms of a Creative Commons Attribution License, which permits unrestricted use, distribution, and reproduction in any medium, provided that the original author and source are credited.

- Este é um artigo publicado em acesso aberto e distribuído sob os termos da Licença de Atribuição Creative Commons, que permite uso irrestrito, distribuição e reprodução em qualquer meio, desde que o autor e a fonte originais sejam creditados.

\section{c) $\mathbf{O}$}


Cada atualização apresentou melhorias em relação a suas antecessoras, mas manteve alguns vícios estruturais das anteriores. Este artigo aborda inconsistências da PND e da END de 2016, tanto no tocante à sua coerência interna quanto à consistência entre si, considerando seus objetivos e sua forma. Por meio de análises de conteúdo, o presente artigo analisa os dois documentos, à luz de conceitos legais, normativos e doutrinários. Pretende-se, assim, contribuir para melhoria qualitativa de tais documentos em suas versões subsequentes.

O debate sobre os documentos de defesa brasileiros tradicionalmente focou um dos documentos de mais alto nível individualmente. O mais analisado é aquele de mais alto nível, a PND (Bertonha 2009; C. W. De Almeida 2010; Rudzit and Casarões 2015). Muito se debateu também sobre a END (P. R. de Almeida 2009; Proença Júnior 2011). Uma análise conjunta da PND e da END de 2012 também foi efetuada (Proença Jr. and Lessa 2018). Mas todas as abordagens foram no sentido de como os documentos dialogavam com a sociedade. O que se pretende aqui é uma abordagem distinta, verificando como os referidos documentos, em sua versão corrente, dialogam entre si.

$\mathrm{O}$ artigo é subdividido em seções relativas a cada aspecto considerado. Inicialmente, aborda-se questões conceituais da diferenciação entre política e estratégia e entre fins e meios. Trata-se, então, dos aspectos legais e normativos da redação jurídica, dado que ambos os documentos têm fundamentação normativa, e mesmo função reguladora, enquanto políticas públicas. Em seguida, avalia-se a questão formalística dos documentos, em particular no tocante à ausência de um padrão de redação e uniformidade do texto, da repetitividade de alguns temas, e da superficialidade de outros. Finalmente, à guisa de conclusão, responde-se à questão proposta.

\section{Dos problemas conceituais}

O primeiro problema nesse âmbito é o da própria diferenciação do que deve constituir uma política, no caso a PND, e uma estratégia, caso da END. As ciências militares, ao menos desde os tempos de Clausewitz, consideram estratégia como a arte de se alocar recursos para a consecução de objetivos políticos. Define-se que "estratégia pública é o uso sistemático de recursos e poderes, por agências públicas, para atingir objetivos públicos" (Mulgan 2009, 19, tradução livre). Adicionalmente, "criar uma estratégia de segurança nacional viável requer uma síntese cuidadosa de funções e instrumentos para alcançar os muitos objetivos que estão sendo perseguidos” (Kugler 2006, 85, tradução livre).

Em essência, o país sábio vê a estratégia de segurança nacional como a "arte do possível" e também do desejável. No entanto, todos os países tentam obter o máximo de benefícios estratégicos dos instrumentos e recursos de que dispõem. Políticas e estratégias que fazem uso efetivo dos instrumentos disponíveis poderão alcançar mais. [...] Assim, [o país sábio] tem um grande incentivo para elaborar políticas e estratégias que empreguem seus instrumentos e recursos da maneira mais eficaz possível, pois isso é muito importante para determinar quanto pode ser alcançado no exterior. Sua necessidade de empregar múltiplos instrumentos políticos em diversas áreas da atividade no exterior compõe os desafios (Kugler 2006, 87, tradução livre). 
A doutrina brasileira de defesa, expressa pela Escola Superior de Guerra (ESG), reflete tais princípios:

Estratégia Nacional é a arte de preparar e de aplicar o Poder Nacional para, superando os óbices, alcançar e preservar os Objetivos Nacionais, de acordo com a orientação estabelecida pela Política Nacional (Brasil 2014, 62).

Poder Nacional, nessa mesma doutrina, é "uma conjugação interdependente de vontades e meios, voltada para o alcance de uma finalidade" (Brasil 2014, 32). Em termos práticos, uma Política Nacional determina fins a serem perseguidos, enquanto uma Estratégia Nacional aloca meios para se atingir os fins estipulados pela política.

A PND apresenta-se como o "documento de mais alto nível" no contexto das políticas públicas para a defesa (Brasil 2016,4). Por conseguinte, espera-se que ela delimite as expectativas da sociedade no tocante aos assuntos de defesa sem, no entanto, avançar sobre temas de outras esferas. Assim, é ela quem deve estabelecer os Objetivos Nacionais de Defesa.

Isso, aliás, encontra-se explicitado no último parágrafo da PND, que estabelece que a PND fixou os objetivos que direcionarão a Estratégia Nacional de Defesa (END). Subordinada a ela, e dentro dos limites por ela impostos, a END, deve definir as ações (e os meios a serem alocados) para a consecução desses objetivos (Brasil 2016, 14).

Outrossim, espera-se que tais documentos atendam a seus objetivos específicos, e que sejam coesos. Internamente a cada um e entre si. No entanto, observa-se que isso não ocorre.

Ainda que, conforme explicitado acima, a PND deva estabelecer os fins, e a END alocar as ações e meios para a consecução daqueles fins, observa-se considerável dificuldade na separação desses itens nos dois documentos. Ao descrever os posicionamentos pelos quais a Defesa Nacional é concebida, temos diversos pontos da PND em que se determina fazer isso visando aquilo, onde fazer isso descreve uma ação ou meio, o que consequentemente deveria estar refletido apenas na END, e visando aquilo é um fim, este sim devendo estar na PND. Pode-se exemplificar o problema com o texto abaixo transcrito:

III. atuar sob a égide de organismos internacionais, visando à legitimidade e ao respaldo jurídico internacional, e conforme os compromissos assumidos em convenções, tratados e acordos internacionais; (Brasil 2016, 11).

Visa-se a "legitimidade e o respaldo jurídico internacional" nas ações de defesa. Esse é o fim; portanto, objeto da PND. "[A]tuar sob a égide de organismos internacionais" "e conforme os compromissos assumidos em convenções, tratados e acordos" é o meio, que deve ser objeto da END. Também, presumivelmente, o país atuará sempre em conformidade com os compromissos internacionais assumidos, e não apenas nesse caso, o que aduz à remoção deste trecho.

Situação similar é encontrada no item VI, "participar de operações internacionais, visando contribuir para a estabilidade mundial e o bem-estar dos povos (Brasil 2016, 11). O fim é "contribuir 
para a estabilidade mundial e o bem-estar dos povos", devendo figurar na PND, e o meio a ser utilizado pelo Ministério da Defesa é “a participação em operações internacionais”, devendo constar da END.

De sua parte o item XIV consiste em "manter as Forças Armadas adequadamente preparadas e equipadas, a fim de serem capazes de cumprir suas missões constitucionais, e prover a adequada capacidade de dissuasão" (Brasil 2016, 12). Neste caso, o fim é dotar as Forças Armadas do preparo e da adequada condição de cumprir suas missões constitucionais (e de demais ordens legais infraconstitucionais também, por suposto), devendo efetivamente constar na PND, enquanto o meio é a manutenção do preparo e equipamentos das Forças Armadas, devendo integrar a END.

Similarmente, no excerto abaixo.

VIII. sem prejuízo da dissuasão, privilegiar a cooperação no âmbito internacional e a integração com os países sul-americanos, visando encontrar soluções integradas para questões de interesses comuns ou afins; (Brasil 2016,11)

O fim político proposto pela PND é o de se "encontrar soluções integradas para questões de interesses comuns ou afins dos países sul-americanos" "sem prejuízo da dissuasão", enquanto o meio, a ser determinado pela END, seria o de se "privilegiar a cooperação no âmbito internacional e a integração com os países sul-americanos".

A menção à dissuasão, tanto no item VIII quanto no XIV, obscurece, como ademais em diversos outros pontos dos documentos, uma questão paralela à mesma, mas de igual importância. A própria PND estabelece, na seção 3 CONCEPÇÃO POLÍTICA DE DEFESA, que "a paz e a estabilidade nas relações internacionais requerem ações integradas e coordenadas" em três esferas (ou pilares): desenvolvimento, diplomacia e defesa. Defesa, por sua vez, é descrita subdividida em dissuasão e enfrentamento de ações hostis (Brasil 2016, 11). Outrossim, dissuasão é uma parte da defesa, e não se confunde biunivocamente com a mesma, como ademais definido na teoria da dissuasão (Snyder 1961, 4). Deve necessariamente ser complementada pela capacidade de enfrentamento de ações hostis. Essa, por sua vez, não aparece explicitada na PND ou na END com a mesma desenvoltura ou frequência, o que nos remete à questão da credibilidade dissuasória, debatida mais adiante.

Além disso, a primeira metade do item 1 INTRODUÇÃO, bem como a quase totalidade do item 2 CONCEPÇÃO ESTRATÉGICA DE DEFESA da END, dizem respeito a elementos de natureza política, de sorte que deveriam estar presentes exclusivamente na PND (Brasil 2016, 16-17).

O segundo problema conceitual a ser tratado é o da própria definição de Defesa Nacional. Enquanto o Objetivo Nacional de Defesa (OND) VIII é fazer com que a sociedade se engaje no debate sobre os temas da Defesa, os dois mais importantes documentos relativos à Defesa Nacional não se entendem quanto ao próprio conceito. De um lado, a PND a conceitua como:

[O] conjunto de atitudes, medidas e ações do Estado, com ênfase na expressão militar, para a defesa do território, da soberania e dos interesses nacionais contra ameaças preponderantemente externas, potenciais ou manifestas (Brasil 2016, 5). 
Por sua vez, a END assim estabelece o conceito:

[O] conjunto de atitudes, medidas e ações do Estado, com ênfase na expressão militar, para a defesa do território, das águas jurisdicionais, da soberania e dos interesses nacionais contra ameaças preponderantemente externas, potenciais ou manifestas (Brasil 2016, 17, grifo nosso).

A END estende a PND, incluindo as águas jurisdicionais. Aqui se materializa um caso em que um documento inferior amplia (e não especializa) o escopo definido por um documento superior, o que não é permitido, como ver-se-á na seção sobre os Aspectos Legais. Ainda, nenhuma das duas definições inclui espaço aéreo, embora o mesmo faça parte do texto descritivo do OND II na própria PND. Mais adiante retornar-se-á à questão do espaço aéreo, ambiente aeroespacial e espaço exterior, que embora conceitualmente diversos são usados indistintamente nos documentos de defesa.

Ao tratar da Capacidade de Proteção, a END avança em sua competência e estabelece juízo de valor, estipulando que tal capacidade exprime o "mais relevante objetivo nacional", aquele que a PND denomina OND I (Brasil 2016, 18). Não cabe à END, mas à PND, estabelecer tal juízo de valor quanto à importância dos objetivos definidos. Enquanto estratégia, aquela deve apenas definir recursos e ações para atingir os objetivos políticos determinados por esta. Ainda que se pudesse advogar que a END estivesse apenas exprimindo uma constatação de prioridade dada pela ordem de numeração dos ONDs estabelecida pela PND, há que se observar que a PND estipula objetivos nacionais de defesa, e não objetivos nacionais, os quais são fixados pela Constituição Federal (CF88) (Brasil 1988).

Prosseguindo no tocante à Capacidade de Proteção, a END estabelece que se "requer a adequação dos meios e métodos de vigilância sobre o território nacional, incluindo a Zona Econômica Exclusiva, a plataforma continental e o espaço exterior sobrejacente, o espaço cibernético e outras áreas de interesse” (Brasil 2016, 19). Novamente observa-se a questão do escopo variável. Em nenhum outro ponto, seja da PND ou da END, há qualquer outra referência à Zona Econômica Exclusiva ou à Plataforma Continental. O "ambiente aeroespacial sobrejacente" foi reduzido a "espaço exterior sobrejacente", abrindo-se mão da vigilância do espaço aéreo. O ciberespaço não está definido na PND, a não ser indiretamente, no item 2.2.17, dentro da descrição do Ambiente Nacional (Brasil 2016, 8). Ainda que diversos países o considerem o quinto domínio da guerra e a END defina a cibernética como um dos setores estratégicos da defesa (Brasil 2016, 30-32). Por fim, se nem a PND nem a END estabelecem o que são "outras áreas de interesse", nenhuma política pública de defesa pode ser esperada para essas áreas. Nenhum recurso será alocado para qualquer capacidade de proteção para essas “outras áreas”.

Há ainda que se considerar que a capacidade de proteção acima descrita está centrada apenas na “vigilância", embora o estipulado pelo OND II seja a "vigilância, o controle e a defesa" (Brasil 2016, 12). Outrossim, os meios previstos pela estratégia serão necessariamente incapazes de satisfazerem os objetivos fixados pela política. Nesse caso, ou se reveem os fins, ou se adequam os meios!

Portanto, para se evitar ambiguidades e conflitos como os aqui destacados, é necessário que a PND estabeleça, possivelmente numa seção Conceitos Fundamentais, de forma clara, o contexto e o 
escopo da defesa. Primeiro, quanto ao que vem a ser território; se inclui ou não as águas jurisdicionais, o espaço aéreo e o espaço exterior sobrejacente, etc. Segundo, quanto ao conceito de soberania utilizado, para o qual uma base inicial poderia ser provida pelo item 2.2.11, que explica que o Brasil "deve considerar a possibilidade de se defrontar com antagonismos que venham pôr em risco seus objetivos nacionais" e que o "eventual enfrentamento desses antagonismos deve ocorrer de forma soberana, consoante os princípios e fundamentos constitucionais e as normas do direito internacional" (Brasil 2016, 7). Terceiro, quanto aos demais interesses a serem defendidos: as linhas de comunicação marítimas (como aquelas fluviais, aéreas, terrestres e cibernéticas), a ZEE, os demais interesses brasileiros (públicos e privados) no exterior, para citar alguns.

Outro problema no campo conceitual é o de que a Concepção Política de Defesa apresentada possui dezoito itens, alguns dos quais não contemplados nos ONDs (Brasil 2016, 11-12). A redação dos itens, utilizando verbos no infinitivo, denota ações, não ideais (geralmente apresentados substantivados). Como ações, devem integrar (ou estar refletidos) nos ONDs, e assim disporem de recursos (meios) determinados na END. Adicionalmente, sua redação deve, onde possível, ser mais direta e menos repetitiva. Exemplificando, é desnecessário repetir, como primeiro item, que o Brasil privilegia a resolução pacífica de controvérsias (Brasil 2016, 11). Isso já está no primeiro parágrafo da PND (e em outros pontos). Ademais, o item seguinte, "apoiar o multilateralismo no âmbito das relações internacionais", em larga medida reflete a disposição anterior.

No tocante às contradições, dever-se-ia evitar o que ocorre no item IV: "repudiar qualquer intervenção na soberania dos Estados" não se coaduna com "e defender que qualquer ação nesse sentido seja realizada de acordo com os ditames do ordenamento jurídico internacional” (Brasil 2016, 11, grifos nossos). Já o item VII inclui uma referência inadequada ao Tratado Sobre a Não-Proliferação de Armas Nucleares (TNP). Ele não é o único tratado internacional relativo aos temas abordados no conjunto da concepção política. Sequer o único relativo ao contexto específico das "armas químicas, biológicas, radiológicas e nucleares”. Nomeá-lo atribui desnecessária relevância ao tema nuclear em relação aos restantes temas da concepção política. Isso traz ao caso das sobras presentes no texto, que podem inserir riscos de interpretação equivocada. Quando o item VIII insere a expressão "sem prejuízo da dissuasão" ele cria o risco de entendimento de que nos demais casos haveria potencial admissibilidade do prejuízo à dissuasão, dada a sua não explicitação, além de fazer com que esse item seja o único (dentre os dezoito) que não inicia por verbo no infinitivo e que tem uma ressalva explicitada (Brasil 2016, 11).

\section{Dos aspectos legais}

O primeiro aspecto legal abordado refere-se à questão da estrutura hierárquica-referencial de documentos de natureza legal. A norma legal máxima do país é a Constituição Federal de 1988 (CF88), a qual define o Estado brasileiro, seus objetivos, e suas instituições, incluindo as Forças Armadas e suas atribuições (Brasil 1988). Abaixo da CF88 temos as chamadas Leis Complementares (LC). Há ainda, em ordem decrescente de importância, 
as Leis Ordinárias, os Decretos e as Portarias Ministeriais. A LC 97 (LC97), alterada pela LC136, detalha as obrigações complementares das Forças Armadas (Brasil 1999; 2010). É a LC97 quem estabelece a precedência da PND, a política, sobre a END, a estratégia, de forma adequada aos moldes conceituais da doutrina de defesa nacional anteriormente apresentados.

O direito não tolera incompatibilidades de normas (antinomia jurídica) (Bobbio 1996, 91-96). No caso em tela, o princípio aplicável é o lex superior derogat inferioris (lei superior derroga a inferior): uma definição superior derroga uma definição inferior. Essa hierarquia faz com que temas definidos pelos documentos de ordem superior sejam imutáveis por aqueles de ordem inferior. Não obstante, outro princípio, o lex specialis derogat generali (lei especial derroga a geral), faz com que os documentos inferiores possam especializar preceitos e conceitos estabelecidos por aqueles superiores, sem, no entanto, contrariá-los. Assim, enquanto a CF88 define os Objetivos Nacionais que devem ser referenciados pela PND, a PND pode fixar os Objetivos Nacionais de Defesa (OND), a serem referenciados pela END.

Do exposto, quando a PND cita os Objetivos Nacionais Fundamentais, referenciando a CF88, resguarda a correta hierarquia (Brasil 2016,4). É sua superiora hierárquica, a CF88, quem estabelece os Objetivos Nacionais a serem perseguidos pela PND. De outra parte, quando ela, por três vezes, referencia o Glossário das Forças Armadas (GFA), aprovado por Portaria Ministerial (por conseguinte um documento subordinado), não observa a correta hierarquia, numa primária inversão de competências. De forma análoga, a END por duas vezes comete o mesmo equívoco de referenciar o GFA (Brasil 2016, 17-18).

Os conceitos, quando necessitarem determinação de escopo, devem ser definidos na PND ou na END, e referenciados pelo GFA, e não o contrário. Cumpre observar que a própria PND utiliza o expediente de definir conceitos no corpo do seu texto, como se observa com as definições de Defesa Nacional, de Segurança Nacional e de Poder Nacional (Brasil 2016, 5). Ainda que a definição de Poder Nacional ali apresentada seja ligeiramente diversa daquela utilizada pela ESG, esta última é mais detalhada e abrangente que a apresentada pela PND, e assim ambas se adequam aos preceitos defendidos por Bobbio.

Exemplo de definição apresentada pela PND é o item 2.2.17 que, discorrendo sobre a importância do ambiente cibernético, descreve o "espaço virtual”1 como composto por

dispositivos computacionais conectados em rede ou não, no qual transitam, processam-se e armazenam-se informações digitais essenciais para garantir o funcionamento dos sistemas de informações, de gerenciamento e de comunicações, dos quais depende parcela significativa das atividades humanas (Brasil 2016, 8, grifo nosso).

1 Ao invés de se utilizar a terminologia "espaço virtual" dever-se-ia utilizar ciberespaço, dado que a definição apresentada faz referência a "dispositivos computacionais". Portanto, a hardware, um ativo concreto e não virtual. 
Trata-se de uma definição de mesmo nível de detalhe daquelas referidas no GFA nos casos citados acima, mas feita pela própria PND. Observe-se que a parte grifada poderia ser suprimida sem perda de conteúdo. Não obstante, essa definição, bem como todas as demais necessárias, deveria integrar uma seção de conceitos específica do documento, o qual conteria todas as definições a serem incorporadas ou referenciadas pelos documentos inferiores.

Diferentemente, ofusca-se a importância da PND quando a mesma, em longa nota de rodapé, conceitua "guerra híbrida" (Brasil 2016, 9). Caso tal definição, nesse documento, se faça de fato relevante, o correto seria transcrever a definição no texto do próprio documento, como no caso do "espaço virtual", e não em uma nota de rodapé. O Glossário das Forças Armadas, então, deverá referenciá-la e incorporá-la. Analogamente, a END faz uso de extensa nota de rodapé para definir “operação em rede", ao invés de defini-la no corpo do texto em uma seção específica para conceitos fundamentais (Brasil 2016, 25).

Por conseguinte, observa-se que, além da quebra da hierarquia referencial, inexiste um padrão para a definição de conceitos, os quais algumas vezes são parte do texto e por outras são notas de rodapé, sendo recomendável uma padronização.

Dado que a PND é o documento de mais alto nível, deve ser ela a fixar os objetivos e preceitos. Assim, deve-se concentrar as definições em uma seção específica dela, eliminando-se quaisquer referências a documentos inferiores. Logo, a seção 2.1 Fundamentos da PND deveria ser subdividida em duas partes. A primeira, contendo Conceitos Fundamentais, onde constariam as definições existentes na atual seção 2.1 Fundamentos da PND, como aquelas de Defesa Nacional, de Segurança Nacional, e de Poder Nacional (Brasil 2016, 5). As seções posteriores, incluindo a nova seção 2.2 Fundamentos, seriam simplificadas, usando apenas os termos definidos. Nesses conceitos fundamentais seriam incorporados outros termos definidos no texto, como o "espaço virtual" e aqueles definidos em notas de rodapé, como "guerra híbrida" e "operação em rede". Com essas definições postas na PND, a END seria também simplificada, sendo dela retiradas definições como as de Defesa Nacional (p. 17) e Poder Nacional (p. 18), redundantes ou mesmo conflitantes com aquelas da PND.

Outro aspecto legal refere-se ao não menos importante problema da denominação da Política: Política Nacional de Defesa ou Política de Defesa Nacional? A Nota Explicativa que acompanhou os documentos estabeleceu:

Em cumprimento ao previsto na Lei Complementar (LC) no 97/1999, alterada pela LC no 136/2010, as minutas da Política Nacional de Defesa (PND), da Estratégia Nacional de Defesa (END) e do Livro Branco de Defesa Nacional (LBDN), correspondentes ao período 2017/2020, foram encaminhadas para apreciação do Congresso Nacional, em novembro de 2016 (Brasil 2016, grifo nosso).

Ocorre que o Art. $9^{\circ}$ da LC97 estipula duas coisas distintas. O $\$ 2^{\circ}$ determina que o LBDN abordará diversos tópicos, dentre os quais a "política nacional de defesa" (Inciso II). Já o $\$ 3^{\circ}$, que trata dos "documentos da defesa", estabelece a apresentação ao Congresso, a cada 4 anos, da "Política de Defesa Nacional" (Inciso I). Este é exatamente o parágrafo citado na capa dos documentos em 
tela. Por conseguinte, o texto, enquanto documento da defesa e não tópico do LBDN, deve ser denominado Política de Defesa Nacional, e não Política Nacional de Defesa. Até eventual alteração do nome estipulado na LC97 não é pertinente que o Ministério da Defesa adote nome diverso. Ao menos sem fazer constar o uso do nome fantasia em substituição àquele determinado pelo arcabouço normativo.

Afora a questão legal, impositiva, outra, de natureza semântica, se apresenta. É necessário esclarecer se o que se pretende adjetivar como nacional são os documentos ou a Defesa. O nome fantasia Política Nacional de Defesa estipula que nacional é a política (a política da nação), e não a defesa. De outra parte, o nome legal Política de Defesa Nacional estipula que nacional é a defesa (a defesa da nação). Neste aspecto, a END e o LBDN refletem cada qual uma ideia diferente. Ainda que para alguns isso parecer pouco relevante, denota uma falta de padrão e uniformidade, normalmente considerados características indeléveis dos militares, os principais, embora por suposto não os únicos, agentes da defesa nacional.

Isso nos traz a outro aspecto: o da responsabilidade coletiva pela defesa. A PND explicita, no item XVIII da Concepção Política de Defesa, que a defesa nacional é responsabilidade não apenas dos militares, mas de toda a sociedade (Brasil 2016, 12). Não obstante, partes dos próprios documentos escorregam e traem esse princípio, como no exemplo do texto sobre o Serviço Militar:

O Serviço Militar deverá ser empregado de acordo com critérios estabelecidos no âmbito das Forças singulares, em função das características e necessidades funcionais e profissionais de cada uma delas. Entretanto, deverá ser observado seu caráter educativo, social e profissionalizante, de modo a entregar à sociedade cidadãos comprometidos com o País e mais bem preparados para o mercado de trabalho, e militares qualificados e motivados para bem servir à Pátria (Brasil 2016, 23, grifo nosso).

Não há aspectos fundamentais em que cidadãos mais bem preparados para o mercado de trabalho se distingam de militares qualificados. Aliás, militares qualificados são exatamente cidadãos mais bem preparados para o seu mercado de trabalho. Similarmente, militares motivados para bem servir à Pátria são cidadãos comprometidos com o País.

Como último aspecto legal temos a questão da incoerência dos Objetivos Nacionais de Defesa na PND. Em seu item 2.1.1, a PND declara que é ela quem estabelece "os objetivos a serem alcançados para assegurar a Defesa Nacional” (Brasil 2016,5). De fato, os mesmos são apresentados à seção 4 como "Objetivos Nacionais de Defesa" (OND) (Brasil 2016, 12-13). Tal denominação especializante está em conformidade com a argumentação anterior sobre a antinomia. Ocorre que os objetivos colocados se tornam um tanto vagos, e incoerentes com as disposições legais superiores.

Exemplificando, o OND I apresentado é “[g]arantir a soberania, o patrimônio nacional e a integridade territorial” (Brasil 2016, 12). A descrição desse objetivo transparece a interpretação do conceito de soberania aplicado: "a condição inalienável de fazer valer a vontade nacional e de exercer a última instância da autoridade do Estado [...] bem como a estabilidade da ordem jurídica" (Brasil 2016, 12). Menos claro é o conceito de patrimônio nacional, mas pode-se entendê-lo como 
“o conjunto de instituições, bens nacionais ${ }^{2}$, direitos e obrigações, valores e costumes" (Brasil 2016, 12). Resta obscuro, no OND I, o conceito de integridade territorial aplicado, pois o texto explicativo restante é apenas "em todo o território nacional".

A questão se mostra ainda mais complexa ao avaliarmos o texto explicativo do OND II, que estabelece a necessidade de se "dotar as Forças Armadas das capacidades para [...] a defesa do território, das águas jurisdicionais e do espaço aéreo brasileiros" (Brasil 2016, 12, grifo nosso). A garantia da soberania e da integridade apenas do território, como dispõe o OND I, mas a defesa, além do território, também das águas jurisdicionais e do espaço aéreo não se coadunam. Isso não corresponde aos objetivos fixados pela PND. Aqui se evidencia, novamente, o problema do escopo da defesa.

Ainda no tocante ao OND II surgem outras questões de consistência. Enquanto o objetivo refere-se ao cumprimento das "missões constitucionais das Forças Armadas", seu texto inclui "prover a segurança das linhas de comunicação marítimas". Neste ponto há dois problemas distintos. Primeiro, não se encontra no texto constitucional essa atribuição das Forças Armadas. Portanto, a PND extrapola o âmbito da "missão constitucional". O mais próximo disso que pode ser encontrado é o estabelecido na LC97, Art. 17, Inciso II, que estabelece, como uma das atribuições subsidiárias da marinha: "prover a segurança da navegação aquaviária”. Entretanto, "navegação aquaviária" é mais do que apenas as "linhas de comunicação marítimas". Poder-se-ia pretender que a PND estivesse limitando o escopo de atuação da Marinha do Brasil (MB) estipulado pela LC97 (e não pela CF88). Não parece, no entanto, o caso de se estabelecer que a força naval atue, de forma parcial, e em apenas uma das suas cinco atribuições subsidiárias exclusivas. Mormente quando não há nenhuma menção às suas outras quatro atribuições ou àquelas do Exército Brasileiro (EB) e da Força Aérea Brasileira (FAB).

Adicionalmente, no restante da descrição do OND II o texto se perde em considerações relativas aos meios, e não aos fins, contrariando o princípio doutrinário dos objetivos de uma política, demonstrado anteriormente. Na mesma toada as descrições dos OND V a VIII também misturam fins e meios. Exemplificando, no OND VI “incrementar a participação do Brasil em organismos e fóruns internacionais" é uma forma de se obter o fim que seria o "incremento da projeção do Brasil no concerto das nações", mas não se descreve o que seria tal incremento (Brasil 2016, 13).

\section{Da forma da redação dos documentos}

O primeiro problema abordado nesta seção refere-se à falta de objetividade e concisão dos textos. Já em seu primeiro parágrafo a PND estabelece a natureza não agressiva do Brasil, que "privilegia a paz e defende o diálogo e as negociações para a solução das controvérsias entre os Estados” (Brasil 2016 , 4). A frase seguinte, no entanto, é absolutamente vaga ao afirmar que "os eventos que marcam a história do país atestam tal postura". Sem detalhar quais eventos, e sem agregar nenhuma informação

2 Caberia uma discussão sobre a aplicabilidade do adjetivo "nacional" apenas aos bens, e não aos demais itens, a qual está fora do presente escopo. 
útil complementar, essa frase pode ser suprimida sem perda para o conteúdo, mas conferindo maior objetividade e concisão ao texto. Tal supressão enquadrar-se-ia na lógica do dito "escrever é a arte de cortar palavras" (Nogueira 2010).

De forma similarmente extensiva e inócua, os três parágrafos subsequentes contam uma breve história da PND, pouco acrescentando aos objetivos finalísticos do documento, os quais poderiam igualmente ser suprimidos, ou ao menos sintetizados em um único parágrafo, menor, elevando a objetividade do texto. Na mesma toada, é uma premissa que a revisão de políticas públicas objetiva "sua adequação às novas circunstâncias, nacionais e internacionais", de sorte que tal explicitação se torna sem sentido (Brasil 2016,4).

O texto também apresenta elementos repetitivos que o tornam desnecessariamente longo. A informação de que o MD é quem coordena o processo de revisão da PND aparece duas vezes à mesma página, não sendo em nenhum dos dois casos de fato necessária (Brasil 2016, 5). Até pelo fato de ser o MD quem as encaminha ao Congresso Nacional e as publica. Similarmente, a natureza não agressiva do Brasil e sua preferência pela solução pacífica de controvérsias e conflitos, tema de abertura do primeiro parágrafo, é repetida nos itens 2.1.5 e 3.2 da PND (Brasil 2016, 6, 11). É também repetido no primeiro parágrafo da $\operatorname{END~(p.~16)~e~novamente~às~páginas~17,~} 23$ e 24 (duas vezes nesta última). Há que se questionar se tal repetição exaustiva não transmite uma mensagem inadequada em um documento dessa natureza. Uma vez destacada já no parágrafo de abertura da PND, a preferência por meios pacíficos já está adequadamente valorizada, sem necessidade de sua reiteração sucessivas vezes. Eventualmente, poder-se-ia manter apenas a repetição também na abertura da END, ainda que desnecessária dada a submissão hierárquica desta à PND.

De outra parte, de forma relativamente surpreendente, considerando-se a natureza dos documentos analisados, o objetivo de defender os interesses nacionais não encontra a mesma ênfase. Em outros termos, nossos documentos de defesa, por definição primordialmente destinados ao emprego da força militar, não valorizam a determinação pela proteção dos interesses nacionais, mas repetidamente reiteram e enfatizam a preferência pela resolução pacífica de controvérsias. De fato, em elevada medida, isso conflita com a proposição de capacidade dissuasória reportada pelos mesmos documentos de defesa. Dissuasão é tradicionalmente modelada como o produto de duas variáveis: capacidade e credibilidade (Brodie 1959; Schelling 1990; 2008; Ganghua and Yongxian 2007). Em termos simples, depende de se possuir os meios para retaliação ou defesa e da sinalização da disposição de se utilizar tais meios.

No tocante às capacidades, os meios militares brasileiros são reconhecidamente limitados quando comparados àqueles de nações de similar porte econômico, demográfico ou territorial no sistema internacional. No tocante à credibilidade de nossa intenção de empregá-los, nossos documentos de defesa sinalizam reiteradamente nossa indisposição em utilizá-los. Portanto, se reduz sensivelmente a capacidade dissuasória nacional na defesa de nossos interesses. Isso pode levar nações menores a arriscarem mais quando da existência de conflitos de interesses, como poderia, hipoteticamente, ter sido o caso da ocupação militar e posterior nacionalização, pela Bolívia, de refinarias da estatal brasileira Petrobras naquele país em 2006. 
$\mathrm{Na}$ mesma linha da falta de objetividade aqui criticada, encontram-se exemplos como os do item 2.2.2 da PND. A menção à “crise atual” e à melhora nos índices socioeconômicos dos últimos anos, ainda insuficientes "para alçar o país à condição de plenamente desenvolvido", não guarda nenhuma relação direta com os objetivos do documento. Assim, é desnecessária, subjetiva e inócua (Brasil 2016, 6).

Também irrelevantes e pouco objetivas são as disposições do item 2.2.4, que poderia ser resumido a "O Brasil carece de maiores investimentos em [c]iência, [t]ecnologia e [i]novação, e em qualificação do capital humano [para a defesa]", uma vez que isso se coaduna com as disposições da PND e da END no tocante ao desenvolvimento de tecnologia nacional de defesa. Já as referências ao logro do Brasil em se integrar "à comunidade de países industrializados" ou ao fato de que os "estrangulamentos de infraestrutura existentes poderão retardar o efetivo desenvolvimento do país" não guardam relação explícita nem com os propósitos nem com o restante dos documentos. Da mesma forma, o item 2.2.18, que trata da matriz energética, extrapola as competências da PND e da END, uma vez que não são citadas ações, planos ou competências de defesa relativos à matriz energética nacional.

No tocante ao impacto das “[m] udanças do [c]lima”, a PND faz uma menção a possíveis "graves consequências ambientais, sociais, econômicas e políticas", sem explicitá-las. E deixa um tanto vaga uma exigência de "maior capacidade estatal de agir" (Brasil 2016, 9). Não há nenhuma clareza sobre o significado de agir, do ponto de vista da defesa, em questões ambientais, sociais, econômicas e políticas. E dado que tal questão, no âmbito da PND, encontra-se no contexto da análise do ambiente internacional, a necessidade de ação estatal precisa indicar os cenários para a ação: uma intervenção internacional por motivação ambiental, social, econômica ou política, por estas ou aquelas nações, em determinadas áreas geográficas. Esse desenho de cenários precisa ser melhor contextualizado: defender-se-á isso, dessa forma, contra tal inimigo. Da forma como está, com objetivos (e ameaças) vagos, a alocação de meios se torna impossível, por ser ilimitada. Por conseguinte, é necessária uma melhor costura dos problemas postos com as ações, ou dos fins com os meios, dando mais clareza e objetividade ao texto.

Ressalte-se que os itens acima citados se diferenciam do item 2.2.5, que trata da falta de regularidade nas aquisições de Produtos de Defesa ou do item 2.2.6, que considera que o porte da economia nacional pode permitir melhores condições de cooperação com nações mais avançadas no âmbito tecnológico ou o aproveitamento de projetos de desenvolvimento, exatamente pelo fato de que, nesses últimos, se explicita a relevância para o tema objeto, a Defesa (Brasil 2016, 6).

A inconsistência das missões-síntese das Forças Armadas, no âmbito da END, é exemplo emblemático da falta de consistência nos objetivos e na linguagem entre os principais atores da defesa. As missões-síntese das Forças Armadas definidas na END são descritas de formas distintas, e em descompasso com suas atribuições constitucionais e subsidiárias, denotando a falta de um arcabouço comum para tais definições (Brasil 2016, 26-30). As diferenças entre as missões das três forças, como se depreende, são tanto de conteúdo quanto de linguagem, o que evidencia a ausência de uma visão comum de missão (portanto de finalidade) das Forças Armadas. As divergências podem ser melhor entendidas pela análise da Tabela 1. 
Tabela 1. Missões-síntese das Forças Armadas conforme a END

\begin{tabular}{l|c|c|c}
\hline Tópico & MB & EB & FAB \\
\hline Contribuir para a defesa da Pátria & $\mathbf{X}$ & & $\mathbf{X}^{*}$ \\
Contribuir para a garantia dos poderes constitucionais & $\mathbf{X}$ & $\mathbf{X}$ & \\
Contribuir para a garantia da lei e da ordem (GLO) & $\mathbf{X}$ & $\mathbf{X}$ & $\mathbf{X}^{*}$ \\
GLO por iniciativa dos poderes constitucionais & $\mathbf{X}$ & & \\
Contribuir para o cumprimento das atribuições subsidiárias previstas em lei & $\mathbf{X}$ & & \\
Contribuir para o apoio à política externa & $\mathbf{X}$ & & \\
Contribuir para a garantia da soberania nacional & & $\mathbf{X}$ & $\mathbf{X}^{*}$ \\
Salvaguardar os interesses nacionais & & $\mathbf{X}$ & \\
Cooperar com o desenvolvimento nacional & & $\mathbf{X}$ & $\mathbf{X}^{*}$ \\
Cooperar com o bem-estar social & & $\mathbf{X}$ & \\
\hline
\end{tabular}

Legenda: $\left(^{*}\right)$ A FAB utiliza linguagem distinta das demais forças singulares.

Fonte: elaborada pelo autor.

Divergências relativas às especificidades de cada domínio operacional (terra, mar, ar, espaço e ciberespaço), quando (e se) aplicáveis, seriam justificáveis e bem entendidas. Mas não é absolutamente o caso, dado que nenhuma das atribuições colocadas nas missões-síntese transparece tais especificidades.

Adicionalmente, chama atenção o fato de que, das treze atribuições que se pode extrair das missões descritas, apenas uma é comum às três Forças Armadas (ainda que com linguagem diferente no caso da FAB): contribuir para a garantia da lei e da ordem. Justamente aquela que denota mais uma questão de segurança interna que uma de "ameaça preponderantemente externa", conforme preconiza a definição de Defesa Nacional da PND (Brasil 2016, 5). E também justamente aquela cujo crescimento dos casos de aplicação das forças militares vem preocupando o Ministério da Defesa (Jungmann 2017). Igualmente relevante é o fato de que ela se destina ao combate ao crime interno, e que este não figura na análise do ambiente interno.

Observa-se, também, uma incongruência entre as Missões-Síntese discutidas acima e os OND’s. Como demonstrado na Tabela 1, há uma divergência entre as missões-síntese das forças singulares apresentadas pela END. Mas a situação se torna mais complexa quando comparamos tais missõessíntese com os OND fixados pela PND. É um exercício complexo de criatividade e flexibilidade fracionar-se os OND em componentes menores e associá-los diretamente às atribuições (linhas) da Tabela 1, extraídas das missões-síntese. Ainda que se possa eventualmente ser bem-sucedido em alguns casos, resulta, no entanto, que nenhuma das Forças Armadas contempla todas as linhas da tabela em sua missão-síntese. Consequentemente, não contempla todos os OND. Exemplifiquemos com o OND I. Garantir a soberania não é parte da missão-síntese declarada da Marinha. Garantir o patrimônio nacional, ainda que considerado como equivalente a "salvaguardar os interesses nacionais", não é missão nem da Marinha, nem da Força Aérea. Garantir a integridade territorial, mesmo se considerada equivalente à "defesa da pátria”, não é parte da missão do Exército. Há também a questão 
da amplitude da ação de cada força singular. O OND I determina que as Forças Armadas, em conjunto, têm o objetivo de "garantir" a soberania. Pode-se entender que nenhuma delas, individualmente, se considerasse em condições de garanti-la sozinha. Logo, faz sentido que optem por utilizar a expressão "contribuir para a garantia", como estipulado nas missões síntese da Marinha e Exército. Não obstante, a Força Aérea desmonta este argumento ao utilizar o verbo "manter", o qual, incidentalmente, não se coaduna com o OND I.

O penúltimo tópico desta seção trata das divergências ou disputas entre as Forças Armadas Singulares. Em 2016, quando publicadas a PND e a END aqui analisadas, o MD já tinha 17 anos de implantação. Mas a PND e a END ainda denotam, em diversos pontos, divergências conceituais (e, por conseguinte, doutrinárias) entre as diferentes forças singulares (Exército, Marinha e Força Aérea). Isso demonstra que mesmo após quase duas décadas o MD ainda não foi capaz de unificar os conceitos doutrinários.

Exemplificando, ao tratar das características intrínsecas (para a Marinha e a Força Aérea) e características doutrinárias (para o Exército), encontramos diferenças importantes, além daquela da própria denominação. A Marinha destaca a mobilidade, a permanência, a versatilidade e a flexibilidade. No entanto, não detalha essas características na END (Brasil 2016, 26). Já o Exército valoriza a flexibilidade, a adaptabilidade, a modularidade, a elasticidade e a sustentabilidade, e faz uma breve descrição de cada uma delas. Acrescenta que não apenas essas características se farão presentes, e adiciona a "capacidade de estar presente" ou "estratégia de presença". Já a Força Aérea, por sua vez, destaca o alcance, a flexibilidade, a versatilidade, a mobilidade, a penetração, a pronta-resposta e a velocidade, sem também detalhá-las. Presumindo que os termos representem mais ou menos o mesmo para cada força, pode-se elaborar a Tabela 2:

Tabela 2. Características Intrínsecas ou Doutrinárias das Forças Armadas conforme a END

\begin{tabular}{|c|c|c|c|}
\hline Característica (intrínseca ou doutrinária) & MB & EB & FAB \\
\hline Adaptabilidade & & $\mathbf{X}$ & \\
\hline Alcance & & & $\mathbf{X}$ \\
\hline Elasticidade & & $\mathbf{X}$ & \\
\hline Flexibilidade & $\mathbf{X}$ & $\mathbf{X}$ & $\mathbf{X}$ \\
\hline Mobilidade & $\mathbf{X}$ & & $\mathbf{X}$ \\
\hline Modularidade & & $\mathbf{X}$ & \\
\hline Penetração & & & $\mathbf{X}$ \\
\hline Permanência & $\mathbf{X}$ & & \\
\hline Presença & & $\mathbf{X}$ & \\
\hline Pronta-resposta & & & $\mathbf{X}$ \\
\hline Sustentabilidade & & $\mathbf{X}$ & \\
\hline Velocidade & & & $\mathbf{X}$ \\
\hline Versatilidade & $\mathbf{X}$ & & $\mathbf{X}$ \\
\hline
\end{tabular}

Fonte: elaborada pelo autor. 
Ainda que se possa desejar presumir, por exemplo, que permanência e sustentabilidade possam ser essencialmente a mesma coisa, confronta-se com dois problemas: o primeiro é a utilização de termos distintos; o segundo, o fato de que nenhuma dessas é uma característica privilegiada pela Força Aérea. Uma série de problemas surge da análise da Tabela 2. Adaptabilidade não haveria de ser importante apenas para o Exército. Alcance não pode importar apenas para a Força Aérea. E assim por diante.

Além das divergências entre as características doutrinárias (ou intrínsecas) acima expostas, transparecem algumas disputas relevantes. Um exemplo é a manifestação relativa à FAB transcrita abaixo:

Considerando que a Força Aérea se configura como uma organização altamente tecnológica, imprescindível se faz utilizar-se das capacidades de proteção dos Sistemas de Comando e Controle e das Estruturas Estratégicas do País, principalmente daquelas que envolvam o espaço cibernético. Deve, portanto, manter em elevado grau o nível de segurança e de defesa dos seus sistemas computacionais (Brasil 2016, 30).

Diversas questões relevantes merecem ser comentadas no tocante a este excerto. A primeira, o fato de que não é apenas a FAB que se configura como uma organização altamente tecnológica. A segunda, a de que não é apenas a FAB que deve manter em elevado grau o nível de segurança e de defesa dos seus sistemas computacionais. Todas as forças singulares necessitam utilizar-se das capacidades de proteção dos sistemas de Comando e Controle. A terceira diz respeito à manifestação "principalmente daquelas que envolvam o espaço cibernético". Ela contraria diretamente o explicitado na própria END, no sentido de que "atribui-se à Marinha a responsabilidade pelo Setor Nuclear, ao Exército pelo Setor Cibernético e à Força Aérea pelo Setor Espacial” e de que a competência cibernética “implica aprimorar [...] a Segurança Cibernética, em todas as instâncias do Estado, com ênfase na proteção das Estruturas Estratégicas relacionadas à Tecnologia da Informação” (Brasil 2016, 31). Por conseguinte, atribuição primordialmente associada ao EB.

Por fim, há a questão das Capacidades Nacionais de Defesa e de seus Sistemas. A END, em seu papel de determinar ações e meios para a consecução de objetivos fixados pela PND, estabelece um conjunto de Capacidades Nacionais de Defesa que se destacam na alocação de parcelas do Poder Nacional: Proteção, Dissuasão, Pronta-resposta, Coordenação e Controle, Gestão da Informação, Mobilidade Estratégica e Mobilização. Para tais capacidades são alocados recursos na forma de Sistemas. A Tabela 3 apresenta as capacidades e os sistemas explicitados. 
Tabela 3. Capacidades Nacionais de Defesa e Seus Sistemas

\begin{tabular}{l|l}
\hline Capacidade & Sistemas \\
\hline \multirow{2}{*}{ Proteção (a) } & $\begin{array}{l}\text { Sistemas de comunicações } \\
\text { Sistemas de informações } \\
\text { Sistemas de alerta relacionados aos órgãos de Proteção e Defesa Civil }\end{array}$ \\
\hline & $\begin{array}{l}\text { Sistema Integrado de Monitoramento de Fronteira (SISFRON) } \\
\text { Sistema de Mísseis e Foguetes } \\
\text { Sistemade Defesa Antiaérea } \\
\text { Sissuação (b) }\end{array}$ \\
\hline Pronta-resposta & Sistema Nacional de Comunicações Críticas (SISNACC) \\
\hline Coordenação e Controle & Sistema Brasileiro de Inteligência (SISBIN) \\
\hline Gestão da Informação & \\
\hline Mobilidade Estratégica & Sistema Nacional de Mobilizacão (SINAMOB) \\
\hline Mobilizacão &
\end{tabular}

Legenda: (a) São referencias a sistemas genéricos.

(b) Não são referidos na seção relativa às Capacidades Nacionais de Defesa, mas na seção específica do Exército Brasileiro (Brasil 2016, 29).

Fonte: elaborada pelo autor.

Da Tabela 3 se depreende que nem todas as capacidades têm sistemas a elas associados. As capacidades de Pronta-resposta e de Mobilidade Estratégica não têm nenhuma citação a sistema que as apoiem. Já a de Proteção tem "sistemas" citados de forma genérica, e nenhuma designação específica para um sistema integrado ou de coordenação interagências. Por outro lado, no tocante à dissuasão, os sistemas indicados foram nomeados não na seção correspondente às capacidades, mas sim na seção relativa ao Exército (Brasil 2016, 29).

Os sistemas não deveriam ser nomeados ou explicitados, principalmente pelo fato de que a lista não parece ser exaustiva. Além disso, a forma apresentada na END permite a interpretação de que algumas capacidades seriam apenas intenções, posto não possuírem o suporte de sistemas, desprestigiando-as em relação às demais. Adicionalmente, não é uma prática comum no contexto internacional que as Estratégias de Segurança Nacionais (National Security Strategies) nomeiem sistemas particulares. Por fim, a designação ou nomeação de sistemas não agrega valor político ou estratégico aos documentos. E se não agrega valor, não há motivos para fazê-la.

\section{Considerações finais}

Como a PND e a END de 2016 dialogam entre si?

Em sua forma atual, os referidos documentos dialogam mal. São ambíguos e contraditórios. Um avança sobre as competências do outro. Não estabelecem claramente sua hierarquia funcional. Não apresentam coerência metodológica entre si, e sequer em si mesmos. 
Mas são documentos de elevada importância para a sociedade brasileira. Constituem relevante ponto de partida para debate e aprofundamento do tema Defesa Nacional, marcadamente ausente no Brasil. Os documentos aqui discutidos, embora encaminhados ao Congresso Nacional em novembro de 2016, somente foram aprovados pelo mesmo, em votações simbólica, sem a realização de consultas públicas ou de debates, em dezembro de 2018. Não tendo sido sancionados, seja pelo Presidente Michel Temer ou pelo Presidente Jair Bolsonaro, não entraram em vigor, permanecendo válidos aqueles de 2012.

A gravidade das deficiências aqui apresentadas é suficiente para indicar a necessidade de uma ampla revisão dos documentos em seu conteúdo, estrutura e forma. E o segundo semestre de 2020 é um ótimo momento para isso, posta a obrigatoriedade da apresentação de suas novas versões.

Os documentos de defesa devem ser simplificados, atendo-se à sua função conceitual essencial. A PND, e apenas ela, deve estipular os conceitos fundamentais, e estabelecer os ONDs de forma direta, clara e concisa. Afinal, são esses os objetivos buscados, os fins pretendidos. Já a END deve se abster de trabalhar conceitos e definições, utilizando a terminologia e preceitos dados pela PND. Enquanto estratégia, deve ocupar-se da alocação de meios para a consecução de fins precisamente estipulados pela PND. Assim procedendo, há uma maior probabilidade de eliminação de redundâncias, contradições, divergências, excessos e falta de uniformidade, os quais permitem incorrer nas inconsistências aqui apontadas.

Tornados mais simples, objetivos e funcionais, os documentos podem tornar-se mais palatáveis e interessantes aos diferentes públicos interessados no tema, fortalecendo as perspectivas de uma discussão que deve ser aprofundada para o bem do Estado e da sociedade brasileiros.

\section{Referências Bibliográficas}

Almeida, Carlos Wellington De. 2010. "Política de Defesa No Brasil: Considerações Do Ponto de Vista Das Políticas Públicas.” Opinião Pública 16 (1): 220-50.

Almeida, Paulo Roberto de. 2009. “Estratégia Nacional de Defesa: Comentários Dissidentes." Meridiano 47, no. 104 (March): 5-9.

Bertonha, João Fábio. 2009. "Uma Política de Defesa Nacional A National Defense Policy." Meridiano 47, no. 103: 24-28.

Bobbio, Norberto. 1996. Teoria Do Ordenamento Juridico. 6th ed. Brasília: Editora UnB.

Brasil. 1988. Constituição Federal de 1988. Congresso Nacional.

—. 1999. Lei Complementar 97. Brasília: Congresso Nacional.

2010. Lei Complementar 136. Brasília: Congresso Nacional.

. 2014. Manual Básico Vol. 1. Rio de Janeiro: ESG.

. 2016. "Política Nacional de Defesa e Estratégia Nacional de Defesa." Brasília.

Brodie, Bernard. 1959. “The Anatomy of Deterrence." World Politics 11 (02): 173-91. https://doi. org/10.2307/2009527. 
Ganghua, Xiang, and Wang Yongxian. 2007. "Preferences, Information and the Deterrence Game." The Chinese Journal of International Politics 1 (3): 309-45. https://doi.org/10.1093/cjip/pom001. Jungmann, Raul. 2017. “A Competência Das Forças Armadas Na Constituição Federal de 1988 e o Seu Papel Na Segurança Interna.” Revista Do Ministério Público Militar 42 (27): 71-81.

Kugler, Richard. 2006. Policy Analysis in National Security Affairs: New Methods for a New Era. National Defense University Press.

Mulgan, Geoff. 2009. The Art of Public Strategy. Oxford University Press.

Nogueira, Armando. 2010. "Escrever é a Arte de Cortar Palavras: De Que Mestre Teria Partido Esta Preciosa Lição?” Portal Da Imprensa. 2010. http://portalimprensa.com.br/noticias/ultimas_ noticias/32240/imprensa+republica+artigo+de+armando+nogueira+sobre+o+desafio+da+edi cao+de+texto.

Proença Jr., Domício, and Marcus Augustus Lessa. 2018. "Brazilian National Defence Policy and Strategy Reviewed as a Unity.” Revista Brasileira de Política Internacional 60 (2). https://doi. org/10.1590/0034-7329201700210.

Proença Júnior, Domício. 2011. “Forças Armadas Para Quê? Para Isso.” Contexto Internacional 33 (2): 333-73. https://doi.org/10.1590/s0102-85292011000200004.

Rudzit, Gunther, and Guilherme Stolle Paixão e Casarões. 2015. "Política de Defesa é Uma Política de Governo." Revista Brasileira de Estudos de Defesa 2 (1): 33-52. https://doi.org/10.26792/rbed. v2n1.2015.54002.

Schelling, Thomas. 1990. The Strategy of Conflict. Harvard University Press. . 2008. Arms and Influence: With a New Preface and Afterword. Yale University Press.

Snyder, Glenn. 1961. Deterrence and Defence: Toward a Theory of National Security. Princeton University Press. 